
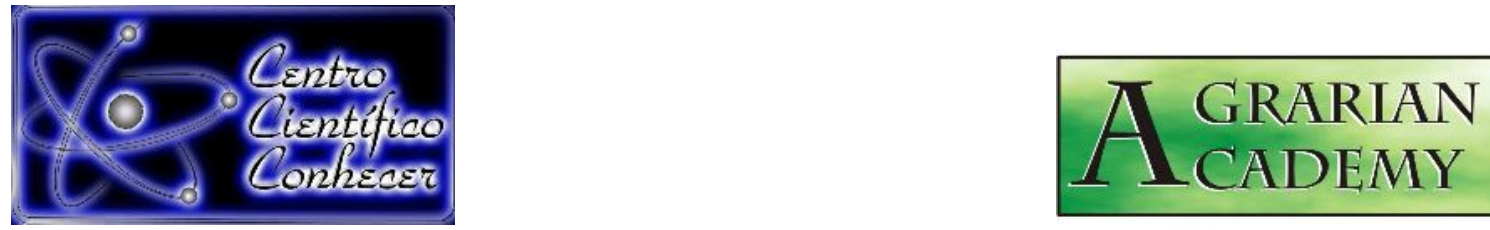

\title{
CARACTERIZAÇÃO MORFOMÉTRICA DA SUB-BACIA HIDROGRÁFICA DO CÓRREGO MURUBIA NO MUNICÍPIO DE MUQUI-ES, BRASIL
}

\footnotetext{
Caio Henrique Ungarato Fiorese ${ }^{1}$, Tiago Oliveira de Aguilar $^{2}$

${ }^{1}$ Graduando em Engenharia Ambiental pelo Centro Universitário São Camilo, Cachoeiro de Itapemirim, Espírito Santo, Brasil. (caiofiorese@hotmail.com).

${ }^{2}$ Graduando em Engenharia de Aquicultura do Instituto Federal do Espírito Santo, Alegre, Espírito Santo, Brasil.

Recebido em: 20/11/2019 - Aprovado em: 15/12/2019 - Publicado em: 30/12/2019 DOI: 10.18677/Agrarian_Academy_2019b1
}

\begin{abstract}
RESUMO
Estudos acerca de bacias hidrográficas são relevantes em virtude de se obter informações necessárias para diversas análises ambientais. Auxiliado por geotecnologias, 0 objetivo deste trabalho foi estimar e caracterizar morfometricamente a sub-bacia hidrográfica do Córrego Murubia (BHCM), no município de Muqui (ES), a fim de diagnosticar potencialidades a alguns problemas ambientais subsidiar melhorias no tocante à qualidade ambiental da região. No sítio eletrônico do Instituto Jones dos Santos (IJSN), foram adquiridas feições de curvas de nível e municípios. Com auxílio do programa ArcMap 10.2 e dos arquivos, foi gerado um Modelo Digital de Elevação da região de interesse para, posteriormente, delimitar a sub-bacia. Foram estimadas as características geométricas, de relevo e drenagem da BHCM, baseando-se na literatura considerada. Verificou-se que a subbacia possui baixa tendência a picos de enchentes em virtude de seu formato irregular. O relevo foi classificado como montanhoso em quase toda a sub-bacia e, juntamente com a elevada amplitude altimétrica, induz a elevada vulnerabilidade a processos erosivos. A BHCM possui elevada densidade de drenagem, porém, baixa densidade de rios, além de requerer uma área de $442,48 \mathrm{~m}^{2}$ para manter perene cada metro de canal hídrico e necessitar de distâncias relativamente elevadas para que cada gota de precipitação percorra até atingir o canal hídrico mais próximo. A implantação de medidas visando minimizar a incidência de processos erosivos e um planejamento correto das atividades antrópicas locais são algumas das medidas para assegurar uma boa qualidade ambiental da BHCM.
\end{abstract}

PALAVRAS-CHAVE: Análise Ambiental; Geoprocessamento; Medidas Mitigadoras. 


\title{
MORPHOMETRIC CHARACTERIZATION OF THE MURUBIA STREAM HYDROGRAPHIC SUB-BASIN IN THE MUNICIPALITY OF MUQUI-ES, BRAZIL
}

\begin{abstract}
Studies about watersheds are relevant because of the necessary information for various environmental analyzes. Aided by geotechnologies, the objective of this work was to estimate and morphometrically characterize the Murubia Stream sub-basin (MSSB), in the municipality of Muqui (ES), in order to diagnose potentialities for some environmental problems and to support improvements in the environmental quality of the region. On the website of the Jones dos Santos Institute (IJSN), contour features and municipalities were acquired. With the aid of the ArcMap 10.2 program and the archives, a Digital Elevation Model of the region of interest was generated to later delimit the sub-basin. The geometric, relief and drainage characteristics of the MSSB were estimated based on the literature considered. It was found that the sub-basin has a low tendency to flood peaks due to its irregular shape. The relief has been classified as mountainous in almost the entire sub-basin and, together with its high altitudes, induces high vulnerability to erosion. The MSSB has a high drainage density, but a low river density, and requires an area of $442,48 \mathrm{~m}^{2}$ to maintain each meter of water channel perennial and require relatively long distances for each drop of precipitation to reach the channel nearest water. The implementation of measures to minimize the incidence of erosive processes and the correct planning of local anthropic activities are some of the measures to ensure a good environmental quality of BHCM.
\end{abstract}

KEYWORDS: Environmental Analysis; Geoprocessing; Mitigating Measures.

\section{INTRODUÇÃO}

A bacia hidrográfica compreende a área geográfica que drena suas águas para um determinado curso d'água principal. Geralmente, são formadas por inúmeras sub-bacias que, por sua vez, possuem inúmeros pequenos riachos que formam a malha de drenagem da grande bacia (SANTOS et al., 2017). Teodoro et al. (2007) conceituam bacias hidrográficas como sendo um conjunto de terras drenadas por um rio e seus afluentes, formada nas regiões mais altas do relevo por divisores de água, onde as águas das chuvas escoam superficialmente formando os riachos e rios ou infiltram no solo para formar as nascentes e o lençol freático.

Nas últimas décadas, as ações antrópicas em bacias hidrográficas têm acarretado sérios danos ambientais, fragilizando o potencial produtivo dos solos e eutrofizando os recursos hídricos, além de gerar outros transtornos (BATISTA et al., 2017). Diante dessa situação, o manejo integrado em microbacias hidrográficas introduz um novo paradigma de gestão e utilização dos recursos naturais. Esse novo padrão de conduta vai ao encontro do conceito de desenvolvimento sustentável do setor agrícola, que tem a preocupação de utilizar sem degradar, preservando efetivamente os recursos naturais para as futuras gerações, integrando o homem ao meio ambiente (SIQUEIRA et al., 2012).

Análises morfométricas de bacias hidrográficas são importantes ferramentas no planejamento e gestão, pois permitem, através de técnicas e procedimentos qualitativos, detalhar o ambiente das mesmas, que se configuram como limites naturais da paisagem (KNIERIN; TRENTIN, 2015). O conhecimento de tais características é essencial para o desenvolvimento de planos visando à 
compreensão dos processos que ocorrem em determinada bacia hidrográfica (SANTOS et al., 2012). A caracterização morfométrica é um dos primeiros e mais comuns procedimentos realizados em análises ambientais e hidrológicas, no intuito de diagnosticar mudanças com ou sem interferência das atividades humanas, buscando o entendimento da dinâmica ambiental (DORIGUEL et al., 2015).

Os processos e métodos do geoprocessamento e sensoriamento remoto estão tendo avanços significativos na sua precisão e velocidade na obtenção de dados. Com o desenvolvimento das geotecnologias, já é possível integrar e reunir vários tipos de dados e informações e, ao mesmo tempo, visualizá-las (PEREIRA; MORAIS, 2015). Apesar dos dados SRTM apresentarem limitações a uma condição ideal de uso (escala, resolução e precisão), sua disponibilidade, associada ao baixo custo de obtenção e de manipulação, torna a modelagem de tais bases uma alternativa viável na aplicação de métodos paramétricos para o estudo do terreno (PIRAJÁ; REZENDE FILHO, 2019).

Auxiliado por geotecnologias e diante da relevância da temática discutida, objetivou-se com este trabalho estimar e caracterizar morfometricamente a subbacia hidrográfica do Córrego Murubia (ES), a fim de diagnosticar potencialidades a alguns problemas ambientais subsidiar melhorias no tocante à qualidade ambiental da região.

\section{MATERIAL E MÉTODOS}

A área estudada compreendeu a sub-bacia do Córrego Murubia (sigla BHCM), que está localizada no município de Muqui, na mesorregião Sul do Estado do Espírito Santo (Figura 1). Possui a cafeicultura e a pecuária como as principais atividades agrícolas, além de ser de grande relevância no abastecimento de regiões à jusante.

FIGURA 1. Localização da BHCM. Fonte: Os Autores (2019).

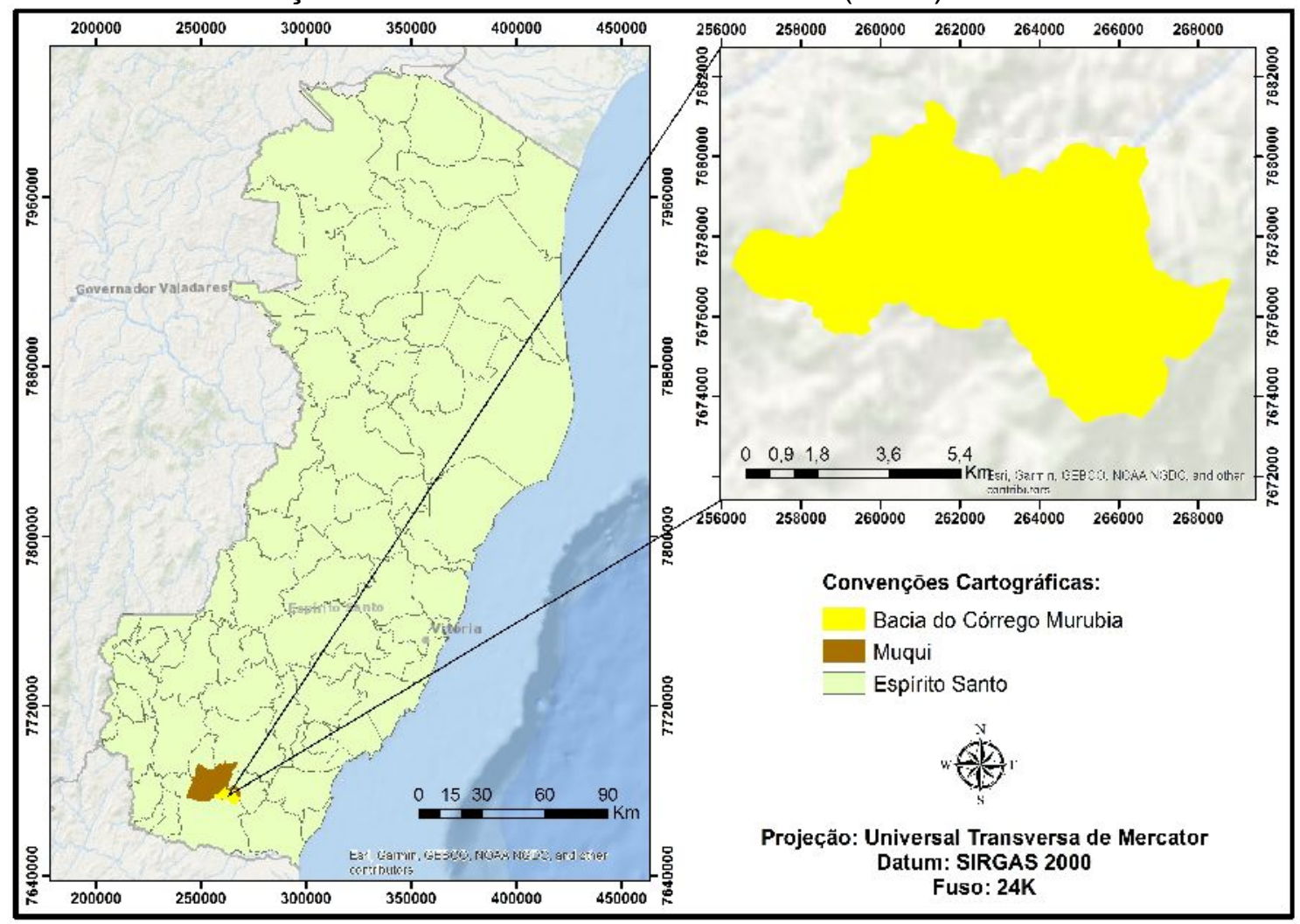


A base de dados utilizada foi o Sistema Integrado de Bases Geoespaciais do Estado do Espírito Santo (GEOBASES) e o sítio eletrônico do Instituto Jones dos Santos (IJSN), em que foram consultados, os arquivos curvas de nivel e municípios, em formato shapefile (shp). Com auxílio do programa ArcMap 10.2 e dos arquivos, foi gerado um Modelo Digital de Elevação (MDE) da região de interesse, a partir das curvas de nível da região estudada, possibilitando os trabalhos posteriores. Os procedimentos de delimitação da BHCM estão resumidos na Figura 2.

FIGURA 2. Fluxograma de delimitação da BHCM. Fonte: Adaptado de Santos et al. (2014).

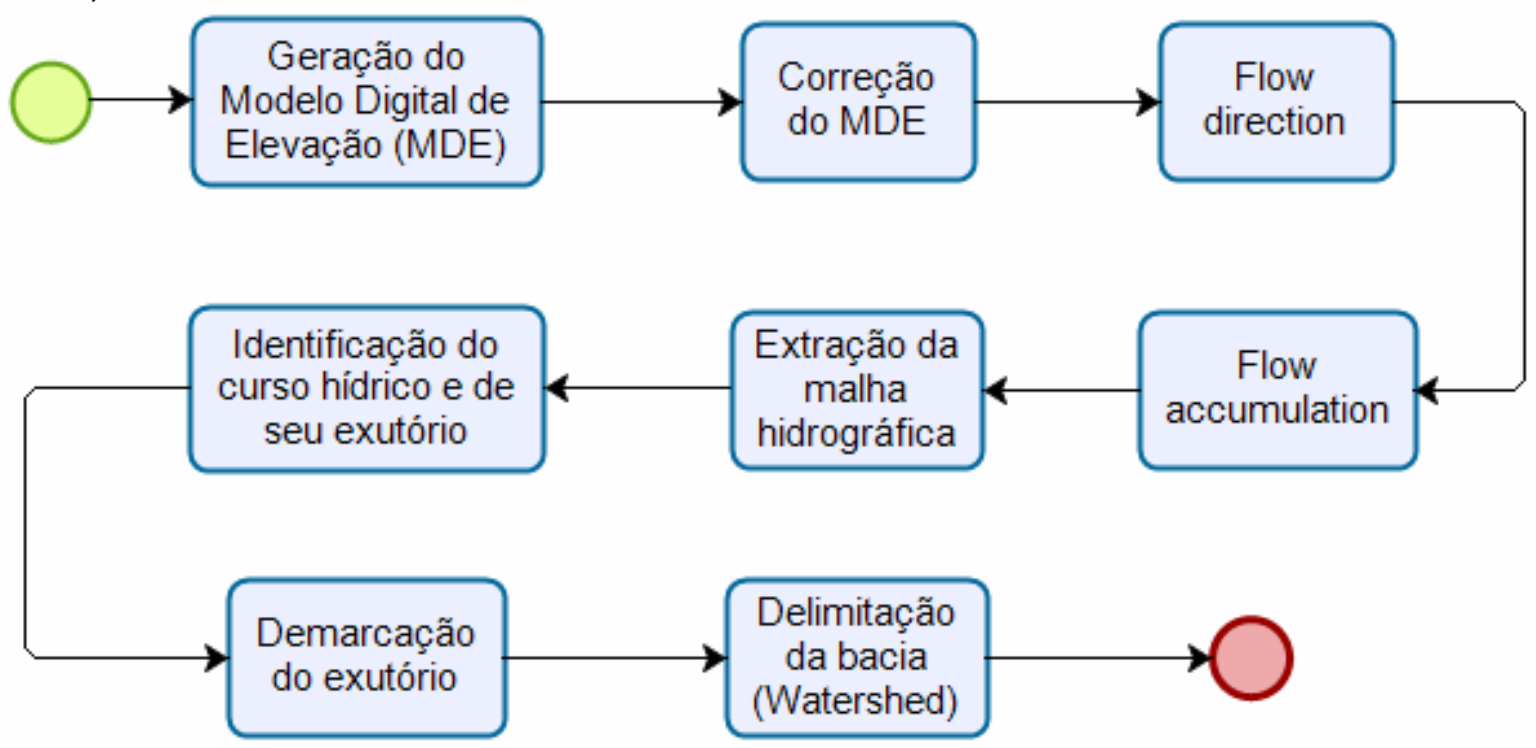

Os procedimentos de determinação dos valores estudados foram semelhantes aos estudos feitos por Sousa e Paula (2016). Através da preparação do banco de dados requerido, foi possível fazer a análise hidrológica da sub-bacia do Córrego Murubia. Nesta pesquisa, foram levantadas, por meio do ArcGIS, as características morfométricas apresentadas e agrupadas no Tabela 1.

TABELA 1. Parâmetros morfométricos determinados

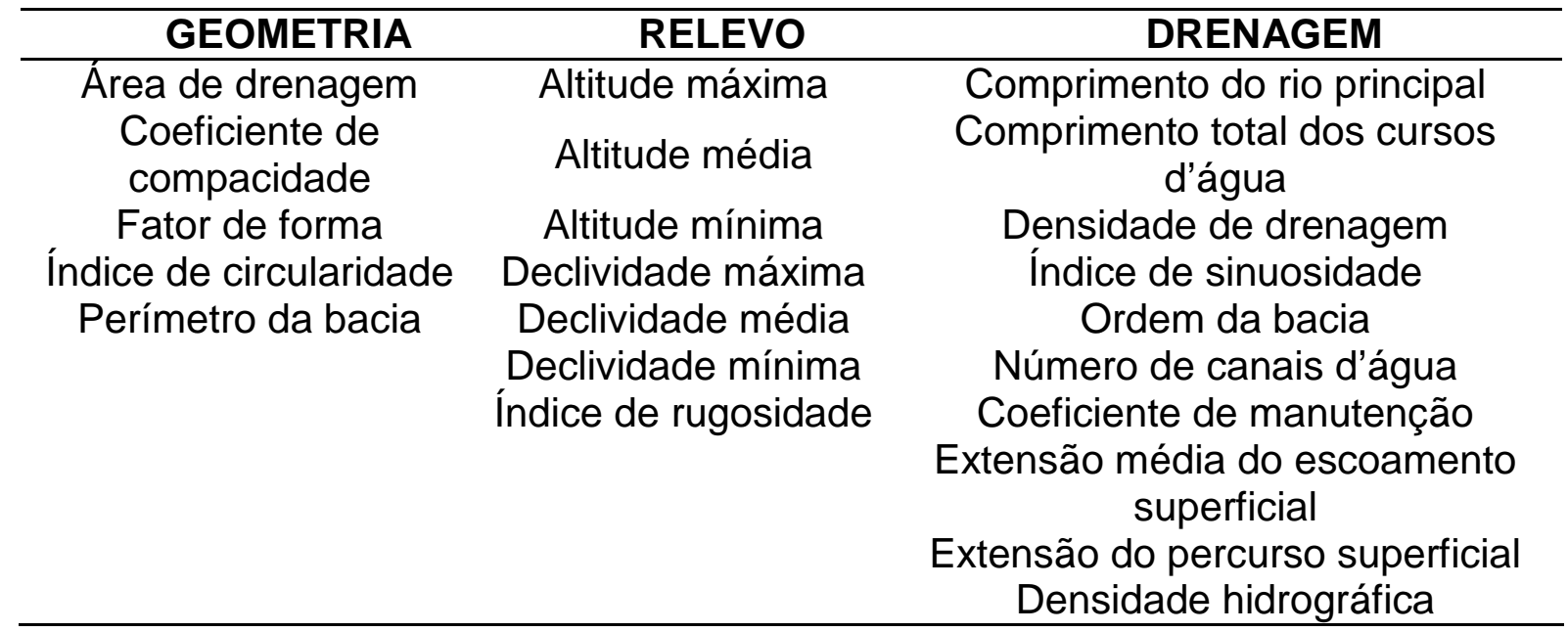

Fonte: Sousa e Paula (2016). 
As altitudes máxima, média e mínima foram estimadas através da geração do MDE, observando, assim, os valores por meio dos recursos estatísticos da tabela de atributos do ArcGIS. Para determinar as declividades, foi gerado um mapa de declividade a partir do MDE, com auxílio dos recursos da aba symbology, nas propriedades do arquivo. A área de drenagem e o perímetro foram obtidos a partir da delimitação da bacia hidrográfica estudada e da edição deste arquivo, em formato shapefile, na tabela de atributos. Os comprimentos do rio principal e de todos os cursos d'água foram obtidos a partir da geração e edição de outro arquivo, a partir também de estimativas feitas na tabela de atributos dos arquivos.

A quantidade total dos canais de drenagem que compõem a bacia foi estimada através da criação de um novo campo na tabela de atributos e do recurso summarize, que permitiu somar o comprimento total dos cursos hídricos e o comprimento dos cursos d'água para cada ordem, que foi classificada para toda a malha hidrográfica com auxílio dos recursos do ícone hydrology, no ArcToolbox. Dessa forma, foi possível gerar também um mapa final acerca da ordem dos cursos hídricos na BHRSA. As equações utilizadas para determinar os demais parâmetros, bem como a literatura consultada, são descritas a seguir:

Coeficiente de compacidade (Kc): Estabelece uma relação entre o perímetro da bacia e a circunferência de um círculo de área igual à da bacia (Georgin et al., 2015). Conforme Villela e Mattos (1975), esse é um coeficiente que varia com a forma de uma bacia, que independe do seu tamanho, sendo calculado pela equação (1):

$$
\mathrm{KC}=0,28 \times \frac{\mathrm{P}}{\sqrt{\mathrm{A}}}
$$

Sendo: $\mathrm{KC}=$ coeficiente de compacidade (adimensional); $\mathrm{P}=$ perímetro da bacia $(\mathrm{Km}) ; \mathrm{A}$ = área da bacia $\left(\mathrm{m}^{2}\right)$. Quanto mais próximo de 1 estiver o valor de $\mathrm{KC}$, mais circular será a forma da bacia, portanto menor será o tempo de concentração de suas águas até o canal principal aumentado a probabilidade de picos de enchentes (CORREIA; BETTINE, 2015).

Fator de forma (Kf): Relaciona a forma de uma bacia com um retângulo, sendo uma razão entre a largura média e o comprimento axial da bacia hidrográfica, desde sua foz até o ponto mais distante (SANTOS et al., 2012). Esse valor foi estimado através da equação (2):

$$
K f=\frac{A}{L^{2}}
$$

Sendo: $\mathrm{Kf}=$ fator de forma; $\mathrm{A}=$ área $\left(\mathrm{Km}^{2}\right) ; \mathrm{L}=$ comprimento axial $(\mathrm{Km})$ (Santos et al., 2012).

Índice de circularidade (Ic): Valores acima de 0,51 indicam bacias hidrográficas alongadas, enquanto valores abaixo de 0,51 indicam bacias mais alongadas (SOUSA; PAULA, 2016). Relaciona os parâmetros área da bacia (A) e perímetro $(P)$, ou seja (equação $(3)$ ): 


$$
\mathrm{Ic}=12,57 \times \frac{\mathrm{A}}{\mathrm{P}^{2}}
$$

Os valores de Kc, Kf e Ic foram classificados conforme mostra a Tabela 2.

TABELA 2. Classificação para o fator de forma (Kf), índice de circularidade (Ic) e coeficiente de compacidade $(\mathrm{Kc})$.

\begin{tabular}{ccccc}
\hline $\mathrm{Kf}$ & $\mathrm{Ic}$ & $\mathrm{Kc}$ & Formato da bacia & Descrição \\
\hline $1,00-$ & $1,0-0,8$ & $1,0-1,24$ & Redonda & $\begin{array}{c}\text { Alta tendência a } \\
\text { enchentes } \\
0,75\end{array}$ \\
$0,75-$ & $0,8-0,6$ & $1,25-1,5$ & Ovalada & $\begin{array}{c}\text { Tendência mediana a } \\
\text { enchentes }\end{array}$ \\
0,50 & & & & $\begin{array}{c}\text { Baixa tendência a } \\
\text { enchentes }\end{array}$ \\
$0,50-$ & $0,6-0,4$ & $1,5-1,7$ & Oblonga & Tendência a conservação \\
0,30 & $<0,4$ & $>1,7$ & Comprida &
\end{tabular}

Fonte: Villela e Mattos (1975).

Índice de rugosidade (IR): evidencia maior diversidade de ambientes e movimento do relevo, culminando na variação das declividades e comprimento das vertentes, além da dimensão das drenagens. Quanto maior esse coeficiente, mais restritiva serão as possibilidades de uso de solo. Ele combina as qualidades de declividade e comprimento das vertentes com a densidade de drenagem, resultando do produto entre a amplitude altimétrica $(\Delta \mathrm{a})$ e a densidade de drenagem (Dd), ou seja, (equação 4)) (MACHADO et al., 2011):

$$
\mathrm{IR}=\Delta \mathrm{a} \times \mathrm{Dd}
$$

O índice de rugosidade pode caracterizar o relevo quanto à declividade, conforme mostra a Tabela 3.

TABELA 3. Classificação do índice de rugosidade

\begin{tabular}{ccc}
\hline CLASSES & VALOR (m) & DESCRIÇÃO DO RELEVO \\
\hline Fraca & $0-150$ & Plano, com declividade média de até 3\% \\
Média & $151-550$ & Suave ondulado com declividade média entre 3\% e 8\% \\
Forte & $551-950$ & Ondulado, com declividade média entre 9\% e 20\% \\
Muito forte & $>950$ & Forte ondulado a montanhoso escarpado, com \\
declividade média superior a 30\%
\end{tabular}

Fonte: Sousa e Rodrigues (2012).

Densidade de drenagem (Dd): Indica a maior ou menor velocidade com que a água deixa a bacia hidrográfica, sendo o índice que indica o grau de desenvolvimento do sistema de drenagem (CURTARELLI, 2009). Esse valor é estimado através da equação (5):

$$
\mathrm{Dd}=\frac{\mathrm{LTC}}{\mathrm{A}}
$$


Sendo: $\mathrm{Dd}=$ densidade de drenagem $\left(\mathrm{Km}^{-1}\right) ; \mathrm{LTC}=$ comprimento total dos cursos d'água $(\mathrm{Km}) ; \mathrm{A}=$ área da bacia $\left(\mathrm{Km}^{2}\right)$.

Índice de sinuosidade (IS): Villela e Mattos (1975) afirmam que é a relação entre o comprimento do rio principal e o comprimento de um talvegue, sendo um fator controlador da velocidade de escoamento e estimado através da equação (6):

$$
I S=\frac{L}{L V}
$$

Sendo: IS = índice de sinuosidade (\%); $L$ = comprimento do rio principal $(\mathrm{m})$ $\mathrm{e} ; \mathrm{Lt}=$ distância vetorial entre os pontos extremos do canal principal $(\mathrm{m})$.

Coeficiente de manutenção $(\mathrm{Cm})$ : significa a área, em metros quadrados, que uma bacia precisa para manter perene cada metro de canal hídrico (SANTOS et al., 2012). Esse valor, estimado através da densidade de drenagem (Dd), é obtido pela equação (7):

$$
\mathrm{Cm}=\left(\frac{1}{\mathrm{Dd}}\right) \times 1000
$$

Extensão do percurso superficial (EPS): segundo Romero et al. (2017), significa a distância média percorrida pelas enxurradas do interflúvio até o canal permanente, sendo uma das variáveis mais importantes que afeta nas partes hidrológica e fisiológica das bacias de drenagem, considerando, nos cálculos, o valor da densidade de drenagem $(\mathrm{Dd})$. Esse valor, dado em $\mathrm{Km}$, pode ser estimado através da equação (8):

$$
\mathrm{EPS}=\frac{1}{2 \times \mathrm{Dd}}
$$

Densidade hidrográfica (Dh): segundo Stipp et al. (2010), "compara a frequência de cursos de água e estima a capacidade de gerar novos cursos hídricos". Esse valor, dado em rios por $\mathrm{Km}^{2}$, é estimado por meio da equação (9):

$$
\mathrm{Dh}=\frac{\mathrm{N}}{\mathrm{A}}
$$

Sendo: $\mathrm{N}=$ número de rios; $\mathrm{A}$ = área da bacia $\left(\mathrm{Km}^{2}\right)$. Os valores da extensão do percurso superficial e das densidades de drenagem e hidrográfica foram classificados conforme a Tabela 4.

TABELA 4. Classificação para a densidade hidrográfica (Dh), densidade de drenagem (Dd) e extensão do percurso superficial (EPS).

\begin{tabular}{cccc}
\hline Dh & $\mathbf{D d}\left(\mathbf{k m} / \mathbf{k m}^{2}\right)$ & EPS $(\mathbf{m})$ & Classificação \\
\hline$<3$ & $<0,50$ & $>1000$ & Baixa \\
\hline $3 \leq \mathrm{Dh}<7$ & 0,50 a 2,00 & 1000 a 249 & Média \\
\hline $\mathrm{Dh} \leq 7<15$ & 2,00 a 3,50 & 248 a 142 & Alta \\
\hline $\mathrm{Dh} \leq 15$ & $>3,50$ & $<142$ & Muito alta \\
\hline
\end{tabular}

Fonte: Sousa e Rodrigues (2012). 
Todos os dados das equações foram estimados por meio de planilha do Microsoft Excel e inseridos em uma tabela, para, posteriormente, estudá-los conforme a literatura considerada e as observações feitas.

\section{RESULTADOS E DISCUSSÃO}

A sub-bacia do Córrego Murubia abrange uma área de $47,93 \mathrm{~km}^{2}$ e um perímetro de 40,22 km. A Tabela 5 apresenta os valores de cada parâmetro geométrico, enfatizando-se os valores de coeficiente de compacidade, fator de forma e índice de circularidade.

TABELA 5. Resultados dos parâmetros geométricos.

\begin{tabular}{cc}
\hline PARÂMETRO & RESULTADO \\
\hline Área de drenagem & $47,93 \mathrm{~km}^{2}$ \\
Coeficiente de compacidade & 1,63 \\
Fator de forma & 0,41 \\
Índice de circularidade & 0,37 \\
Perímetro & $40,22 \mathrm{~km}$ \\
\hline
\end{tabular}

Os parâmetros calculados, de acordo com a classificação considerada, indicam que a BHCM possui baixa vulnerabilidade à ocorrência de picos de enchentes, pois os valores de coeficiente de compacidade, fator de forma e índice de circularidade foram afastados de 1 pois, segundo Villela e Mattos (1975), bacias com tais características indicam que a mesma é extensa, longa e com formato irregular, o que reduz as possibilidades de uma precipitação pluviométrica abranger toda a bacia. No caso de bacias com valores próximos a 1, Villela e Mattos (1975) explicam que esses valores indicam formato mais circular e, por isso, há maior possibilidade a enchentes pelo fato de uma precipitaçaõ pluviométrica ter mais possibilidades de abranger toda a extensão da bacia hidrográfica.

Em outras palavras, Correia e Bettine (2015) explicam que bacias hidrográficas com formato mais circular possuem menor tempo de concentração de suas águas até atingirem o canal principal, o que aumenta a potencialidade à enchentes. Portanto, a BHCM possui características que indicam baixa potencialidade a enchentes, além de um maior tempo de concentração que não favorece o acúmulo imediato da água no canal principal após a ocorrência de precipitações pluviométricas.

$\mathrm{Na}$ caracterização do relevo, foram vistos valores de amplitude altimétrica e clinométrica iguais a $1080 \mathrm{~m}$ e 582,46\%, respectivamente. A Tabela 6 apresenta detalhadamente os resultados das características de relevo consideradas e as Figuras 3 e 4 mostram os mapas altimétrico e clinométrico, respectivamente.

TABELA 6. Resultados dos parâmetros de relevo

\begin{tabular}{cc}
\hline PARÂMETRO & RESULTADO \\
\hline Altitude máxima & $1260,00 \mathrm{~m}$ \\
Altitude média & $556,48 \mathrm{~m}$ \\
Altitude mínima & $180,00 \mathrm{~m}$ \\
Amplitude altimétrica & $1080,00 \mathrm{~m}$ \\
Declividade máxima & $582,46 \%$ \\
Declividade média & $46,06 \%$ \\
Declividade mínima & $0 \%$ \\
Amplitude clinométrica & $582,46 \%$ \\
Índice de rugosidade & 2440,80 \\
\hline AGRARIAN ACADEMY, Centro Científico Conhecer - Goiânia, v.6, n.12; p.8 & 2019
\end{tabular}


FIGURA 3. Mapa de altitude. Fonte: Os Autores (2019).

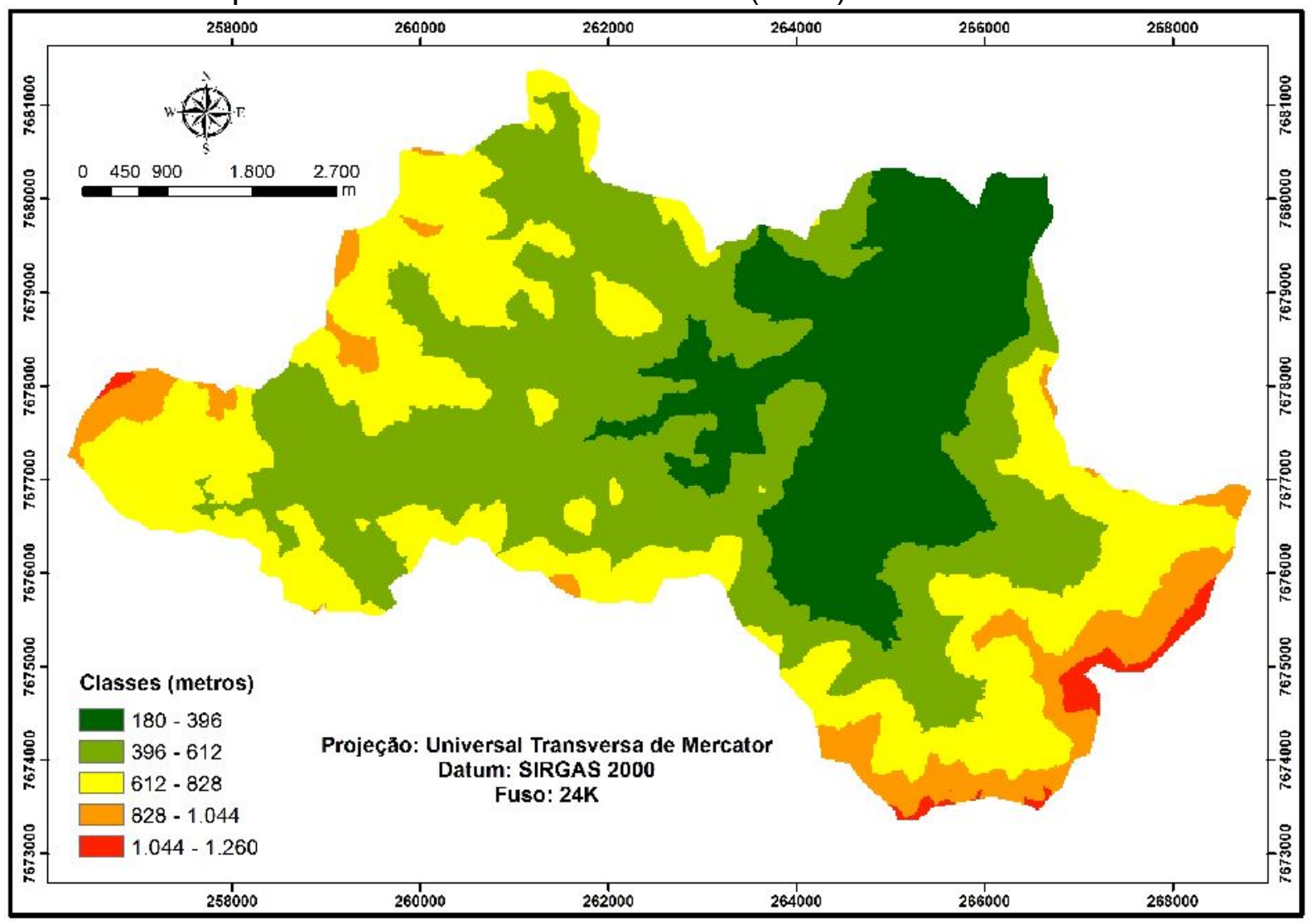

FIGURA 4. Mapa de declividade. Fonte: Os Autores (2019).

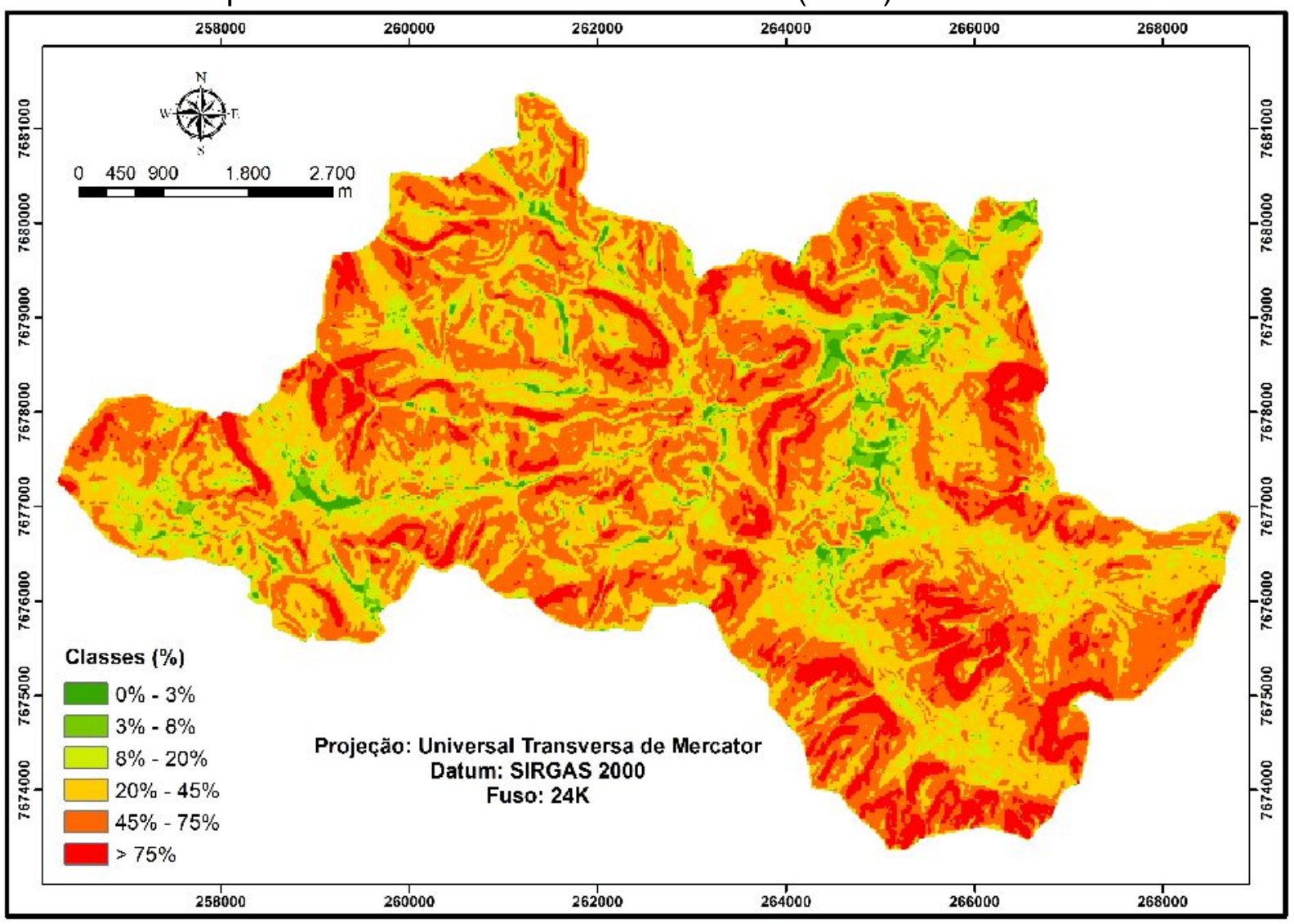


A amplitude altimétrica é elevada na BHCM, assim como a declividade que, por sua vez, indica que a sub-bacia possui relevos que variam de plano a escarpado. Mas, a declividade média da sub-bacia classifica o relevo como montanhoso (acima de 45\%). Isso indica, portanto, elevadas irregularidades do relevo da BHCM. A declividade é um parâmetro que deve ser observado em bacias hidrográficas, pois, áreas que apresentam declividade acentuada apresentam acelerada concentração da água da chuva, o que influencia significativamente na ocorrência de picos de enchentes (SOUZA et al., 2017). Já a altitude influencia nas diferenças de temperatura na bacia, além de seus mecanismos de evaporação e da forma com que a precipitação é captada. Outra influência relacionada a altas altitudes é a retenção maior de umidade, com formação de neblinas, gerando microclimas (BERTOSSI et al., 2011). Fenômenos estes evidentes na BHCM devido à altitudes que passam de $1000 \mathrm{~m}$ em alguns pontos, favorecendo a geração de microclimas e neblinas.

Conforme visto no mapa clinométrico, as classes de declividade compreendidas de 0 a $8 \%$ estão distribuídas em baixas áreas ao longo da sub-bacia. Estes locais caracterizam-se por serem áreas planas onde ocorrem processos de acumulação de sedimentos fluviais, e por serem áreas suscetíveis a inundações, em decorrência do extravasamento das águas dos canais d'água (KNIERIN; TRENTIN, 2015). Porém, há predominância das classes de declividade acima de $20 \%$, o que, segundo Knierin e Trentin (2015), relevos com tal característica tendem a apresentar processos erosivos intensos, o que prejudica as práticas agrícolas e pecuárias na $\mathrm{BHCM}$ e a sua qualidade ambiental.

O índice de rugosidade obtido foi classificado como "muito forte", caracterizando o relevo como forte ondulado a montanhoso escarpado, com declividade média superior a 30\%. Esse parâmetro evidência maior diversidade de ambientes e maior movimento do relevo, o que implica na variação das declividades e comprimento das vertentes, além da dimensão das drenagens. Quanto maior esse coeficiente, mais restrita serão as possibilidades de uso, como a irrigação (VENCESLAU; MIYAZAKI, 2019). Portanto, a rugosidade da BHCM atesta para elevadas iregularidades no relevo, o que restringeas possibilidades de uso da terra para diversos fins antrópicos em boa parte de sua área e também na maior intensidade à processos erosivos.

Diante dessa situação, a declividade associada a cobertura vegetal tornam-se fatores importantes na tomada de decisão de um manejo adequado da bacia hidrográfica, visto que influenciam a precipitação efetiva, escoamento superficial e fluxo de água no solo, dentre outros (SILVA et al., 2018). Por isso, a cobertura vegetal adequada na BHCM assume um papel eficaz para minimizar a erosão dos solos locais, devido às irregularidades no relevo, pois contribui também para reduzir o escoamento superficial e melhorar a qualidade ambiental desta sub-bacia. A Tabela 7 mostra os resultados das características de drenagem, destacando-se os valores de coeficiente de manutenção, densidades de drenagem e hidrográfica, extensão do percurso superficial e índice de sinuosidade. Quanto à ordem segundo a classificação de Strahler, a BHCM é de ordem 6. 
TABELA 7. Resultados dos parâmetros de drenagem

\begin{tabular}{cc}
\hline PARÂMETRO & RESULTADO \\
\hline Coeficiente de manutenção & $442,48 \mathrm{~m}^{2}$ \\
Comprimento do rio principal & $13,27 \mathrm{~km}$ \\
Comprimento total dos cursos d'água & $108,33 \mathrm{~km}$ \\
Densidade de drenagem & $2,26 \mathrm{~km} / \mathrm{km}^{2}$ \\
Densidade hidrográfica & $4,63 \mathrm{rios} / \mathrm{km}^{2}$ \\
Extensão do percurso superficial & $221,20 \mathrm{~m}$ \\
Índice de sinuosidade & $1,27 \%$ \\
Ordem da bacia & 6 \\
\hline
\end{tabular}

O coeficiente de manutenção obtido indica que a BHCM necessita de 442,48 $\mathrm{m}^{2}$ para abastecer cada metro de canal d'água local. Esse valor evidencia áreas de recarga (VENCESLAU; MIYAZAKI, 2019) e, embora não tenha sido classificado, foi superior ao obtido em outras bacias hidrográficas, como a sub-bacia do Córrego Amorim $\left(355,872 \mathrm{~m}^{2}\right.$, segundo Fiorese e Torres (2019)). Portanto, o valor obtido para a BHCM foi razoável em termos de abastecimento hídrico, o que influi em áreas relativamente maiores para manter perenes os seus canais d'água.

A densidade de drenagem obtida foi classificada como alta. Segundo Venceslau e Miyazaki (2019), áreas muito drenadas possuem tendência a processos erosivos mais intensos e, por isso, merecem atenção quanto às práticas de manejo e conservação da mata ciliar. Portanto, a BHCM possui alta tendência a processos erosivos, também justificada pelas características do relevo. Por ser uma área rural, significa um alerta mediante as atividades agrícolas e pecuárias ali executadas.

A densidade hidrográfica calculada foi classificada como "média". No entanto, foi inferior aos valores obtidos em outras bacias, como a sub-bacia hidrográfica do Córrego Amorim (11,591 rios $/ \mathrm{km}^{2}$, segundo Fiorese e Torres (2019)). Quanto à extensão do percurso superficial, o valor estimado foi classificado como "muito alto". Isso indica que a BHCM necessita de distância relativamente elevadas para que cada gota de precipitação pluviométrica, ao atingir a superfície terrestre, percorra até atingir o canal hídrico mais próximo. De acordo com Fiorese e Torres (2019), valores baixos desse parâmetro indicam um rápido abastecimento aos cursos hídricos de uma bacia, ao passo que valores elevados atestam para maior lentidão no abastecimento dos cursos hídricos, como é o caso da BHCM.

O índice de sinuosidade é a variável que descreve a velocidade do fluxo do curso hídrico, em que quanto menor a sinuosidade, menos dificuldade o curso hídrico encontrará para chegar até sua foz, e com sinuosidade elevada, maior será a dificuldade (BATISTA et al., 2017). Valores próximos a 1,0 indicam que o canal tende a ser retilíneo. Já os valores superiores a 2,0 sugerem canais tortuosos e os valores intermediários indicam formas transicionais, regulares e irregulares (LANA et al., 2001). Portanto, a sinuosidade do canal principal da BHCM é caracterizada como retilínea, pois o valor obtido foi mais próximo de 1,0 . Assim, o fluxo d'água não possui elevadas dificuldades para atingir a foz da BHCM, ou seja, há maior rapidez para a água caminhar no entorno do canal hídrico principal. Com um índice acima de 2,0 de sinuosidade, caracteriza-se por redes de drenagem sinuosas, podendo haver acúmulos de sedimentos, o que pode ser agravado pela ação antrópica (STIPP et al., 2010), o que não é o caso da BHCM. 


\section{CONCLUSÃO}

A BHCM possui baixa tendência à picos de enchentes em decorrência de seu formato irregular, constutindo um fator positivo para a qualidade ambiental e à manutenção das atividades antrópicas locais. Todavia, as elevadas irregularidades no relevo e a alta densidade de drenagem evidenciam alta tendência à processos erosivos, o que pode ser agravado caso não seja praticado algumas medidas de mitigação e atenuação. Além disso, as elevadas distâncias médias percorridas pelas gotas de precipitação pluviométrica prejudicam o abastecimento dos cursos hídricos locais. Conforme visto no valor médio da densidade hidrográfica. O coeficiente de manutenção indica que a BHCM necessita de áreas maiores para manter perene cada metro de canal hídrico, o que indica também maior lentidão no abastecimento dos canais d'água.

Portanto, são necessárias medidas que visem à minimiação dos processos erosivos como, por exemplo, um planejamento correto das atividades antrópicas locais e trabalhos de educação ambiental com os moradores da sub-bacia, no intuito de melhorar a qualidade ambiental da BHCM atrelada ao crescimento econômico na região.

\section{REFERÊNCIAS}

BATISTA, D. F.; CABRAL, J. B. P.; ROCHA, T.; BARBOSA, G. R. Caracterização morfométrica da bacia hidrográfica do Ribeirão Santo Antônio - GO. Geoambiente Online, Jataí, n. 29, p. 15-35, 2017. Disponível em: <https://revistas.ufg.br/geoambie nte/article/view/50882>. Doi: https://doi.org/10.5216/revgeoamb.v0i29.50882

BERTOSSI, A. P. A.; KLIPPEL, V. H.; PELUZIO, T. M. de O.; MENEZES, J. P. C. de.; CECíLIO, R. A. Análise morfométrica da sub-bacia do Córrego Horizonte, Alegre-ES, utilizando o Sistema de Informação Geográfica (SIG). Nucleus, Ituverava, v. 8, n. 2, p. 209-218, nov. 2011. Disponível em: <http://www.nucleus.feituverava.com.br/index.php/nucleus/article/view/608>. Doi: http://dx.doi.org/10.3738/nucleus.v8i2.608

CORREIA, L. E.; BETTINE, S. do C. Caracterização física da bacia hidrográfica do córrego Brandina, Campinas - SP. In: ENCONTRO DE INICIAÇÃO CIENTÍFICA, 10., 2015, Campinas. Anais... Campinas: PUC, 2015.

CURTARELLI, M. P. SIG aplicado à caracterização morfométrica de bacias hidrográficas - estudo de caso da bacia hidrográfica do rio Cubatão do Sul - Santa Catarina/Brasil. In: SIMPÓSIO BRASILEIRO DE SENSORIAMENTO REMOTO, 14., 2009, Natal. Anais... Natal: Instituto Nacional de Pesquisas Espaciais, 2009.

DORIGUEL, F.; CAMPOS, S.; DELMANTO JUNIOR, O. Caracterização morfométrica da microbacia do Córrego Maria Pires, Santa Maria da Serra, Estado de São Paulo, Brasil. Energia na Agricultura, v. 30, n. 4, p. 372-377, 2015. Disponível em: <http://revistas.fca.unesp.br/index.php/energia/article/view/1867>. Doi: https://doi.org/10.17224/EnergAgric.2015v30n4p372-377

FIORESE, C. H. U.; TORRES, H. Morfometria da sub-bacia hidrográfica do Córrego Amorim, em Muniz Freire-ES, Brasil. Enciclopédia Biosfera, Goiânia, v. 16, n. 29, p. 157-172, 2019. Disponível em: < http://www.conhecer.org.br/enciclop/2019a/agrar/ morfometria.pdf>. Doi: 10.18677/EnciBio_2019A11 
GEOBASES. lema - mapeamento ES - 2012-2015. Disponível em: $<$ https://geobases.es/gov.br/links-para-mapes1215>.

GEORGIN, J.; OLIVEIRA, G. A.; ROSA, A. L. D. Estudo comparativo de índices morfométricos relacionado com cheias nas bacias hidrográficas do alto Jacuí e Vacacaí - Vacacaí Mirim - RS. Revista Eletrônica em Gestão, Educação e Tecnologia Ambiental, Santa Maria, v. 19, n. 2, p. 1357-1364, mai./ago. 2015. Disponível em: <https://pdfs.semanticscholar.org/e108/28d51d54ffe025034d86a09d 0452c694f93f.pdf>. Doi: 105902/2236117016834

INSTITUTO JONES DOS SANTOS NEVES. Shapefiles. Disponível em: <http://www.ijsn.es.gov.br/mapas/>

KNIERIN, I. S.; TRENTIN, R. Análise de parâmetros morfométricos da bacia hidrográfica do Arroio Lajeado Grande (RS). Ciência e Natura, Santa Maria, v. 37, n. 4, p. 405-421, 2015. Disponível em: <https://www.redalyc.org/pdf/4675/46754619 4034.pdf>. Doi: http://dx.doi.org/105902/2179460X15906

LANA, C. E.; ALVES, J. M. P.; CASTRO, P. T. A. Análise morfométrica da bacia do Rio do Tanque, MG - Brasil. Revista Escola de Minas, v. 54, n. 2, abr./jun. 2001. Disponível em: <http://www.scielo.br/scielo.php?script=sci_arttext\&pid=S037044672001000200008> Doi: http://dx.doi.org/10.1590/S0370-44672001000200008

MACHADO, R. A. S.; LOBÃO, J. S. B.; VALE, R. de M. C.; SOUZA, A. P. M. J. Análise morfométrica de bacias hidrográficas como suporte a definição e elaboração de indicadores para a gestão ambiental a partir do uso de geotecnologias. In: Simpósio Brasileiro de Sensoriamento Remoto, 15., 2011, Curitiba. Anais... Curitiba: Instituto Nacional de Pesquisas Espaciais, 2011.

PEREIRA, T. K. K.; MORAIS, J. F. Técnicas de geoprocessamento aplicadas aos problemas ambientais que afetam o rio laco dentro do limite municipal de Sena Madureira-AC. Revista Eletrônica em Gestão, Educação e Tecnologia Ambiental, v. 19, n. 1, p. 11-20, jan./abr. 2015. Disponível em: <https://periodicos.ufsm.br/reget/article/view/13867>. Doi: http://dx.doi.org/10.5902/2 236117013867

PIRAJÁ, R. V.; REZENDE FILHO, A. T. Análise morfométrica da bacia hidrográfica do Córrego Ceroula em Mato Grosso do Sul. Revista GeoFronter, v. 1, n. 5, p. 3558, 2019. Disponível em: <https://periodicosonline.uems.br/index.php/GEOF/article/vi ew/3452>.

ROMERO, V.; FORMIGA, K. T. M.; MARCUZZO, F. F. N. Estudo hidromorfológico de bacia hidrográfica urbana em Goiânia/GO. Ciência e Natura, Santa Maria, v. 39, n. 2, p. 320-340, 2017. Disponível em: <http://rigeo.cprm.gov.br/xmlui/handle/doc/17 706>. Doi: $10.5902 / 2179460 \times 26411$

SANTOS, D. B.; VIDOTTO, M. L.; BERTINATTO, R.; MARCON, G. R. S.; FRIGO, E. P. Caracterização morfométrica da bacia hidrográfica do Rio São José, Cascavel, PR. Revista Brasileira de Tecnologia Aplicada nas Ciências Agrárias, v. 5, n. 2, 
p. 7-18, 2012. Disponível em: <https://revistas.unicentro.br/index.php/repaa/article/vi ew/1659>. Doi: 10.5777/PAeT.V5.N2.01

SANTOS, A. R. dos.; EUGÊNIO, F. C.; RIBEIRO, C. A. A. S.; SOARES, V. P.; MOREIRA, M. A. et al. ArcGIS 10.2.2 passo a passo: elaborando meu primeiro mapeamento. 1.ed. Alegre: CAUFES, 2014. 55 p.

SANTOS, L. B. L. dos.; VASCONCELLOS, P.; MIRANDA, T. N. S.; CARVALHO, S. $\mathrm{V}$. de. Pontes conceituais entre matemática e redução de risco de desastres socioambientais - o conceito de bacia hidrográfica estocástica. Revista Percursos, Florianópolis, v. 18, n. 36, p. 125-136, 2017. Disponível em: < http://www.revistas.ud esc.br/index.php/percursos/article/view/1984724618362017125/pdf>. Doi: 10.5965/1 984724618362017125

SILVA, G. C.; ALMEIDA, F. P.; ALMEIDA, R. T. S.; MESQUITA, M.; ALVES JUNIOR, J. Caracterização morfométrica da bacia hidrográfica do Riacho Rangel-Piauí, Brasil. Enciclopédia Biosfera, Goiânia, v. 15, n. 28, p. 244-258, 2018. Disponível em: $<$ https://www.conhecer.org.br/enciclop/2018B/AGRAR/caracterizacao\%20morfometri ca.pdf>. Doi: 10.18677/EnciBio_2018B22

SOUSA, F. R. C.; PAULA, D. P. Caracterização morfométrica da bacia hidrográfica do rio Tapuio (Ceará - Brasil). Revista de Geociências do Nordeste, v. 2, p. 555564, 2016. Disponível em: <https://periodicos.ufrn.br/revistadoregne/article/view/104 $99 / 7430>$.

SOUZA, C. F. de.; PERTILLE, C. T.; CORRÊA, B. J. S.; VIEIRA, F. S. Caracterização morfométrica da bacia hidrográfica do Rio Ivaí - Paraná. Geoambiente Online, Jataí, n. 29, p. 93-110, 2017. Disponível em: <https://revistas.ufg.br/geoambiente/article/view/50602>. Doi: https://doi.org/10.5216/ revgeoamb.v0i29.50602

STIPP, N. A. F.; CAMPOS, R. A.; CAVIGLIONE, J. H. Análise morfométrica da subbacia hidrográfica do Rio Taquara - uma contribuição para o estudo das ciências ambientais. Portal da Cartografia, Londrina, v. 3, n. 1, p. 105-124, 2010. Disponível em: < http://www.uel.br/revistas/uel/index.php/portalcartografia/article/view/8929/745 $1>$.

TEODORO, W. L. I.; TEIXEIRA, D.; COSTA, D. J. L.; FULLER, B. B. O conceito de bacia hidrográfica e a importância da caracterização morfométrica para 0 entendimento da dinâmica ambiental local. Revista UNIARA, n. 20, p. 137-157, 2007. Disponível em: < https://www.uniara.com.br/legado/revistauniara/pdf/20/RevUn iara20_11.pdf>. Doi: https:10.25061/2527-2675/ReBraM/2007.v11i1.236.

VENCESLAU, F. R.; MIYAZAKI, L. C. P. Processos, análises e gestão de bacias hidrográficas em ambientes urbanos: o caso do Córrego São José - Ituiutaba/MG. Revista Geografia em Atos, Presidente Prudente, v. 2, n. 9, p. 71-92, 2019. Disponível em: < http://revista.fct.unesp.br/index.php/geografiaematos/article/view/63 42/pdf_1>.

VILLELA, S. M.; MATTOS, A. Hidrologia aplicada. São Paulo: McGraw-Hill, 1975. 